\title{
Atopic dermatitis is a serious health problem in Poland. Epidemiology studies based on the ECAP study
}

\author{
Adam J. Sybilski ${ }^{1,2}$, Filip Raciborski ${ }^{3}$, Agnieszka Lipiec ${ }^{1}$, Aneta Tomaszewska ${ }^{1}$, Adam Lusawa ${ }^{1}$, Piotr Samel-Kowalik ${ }^{1}$, \\ Artur Walkiewicz ${ }^{1}$, Edyta Krzych ${ }^{1}$, Jarosław Komorowski ${ }^{1}$, Bolesław Samoliński ${ }^{1}$

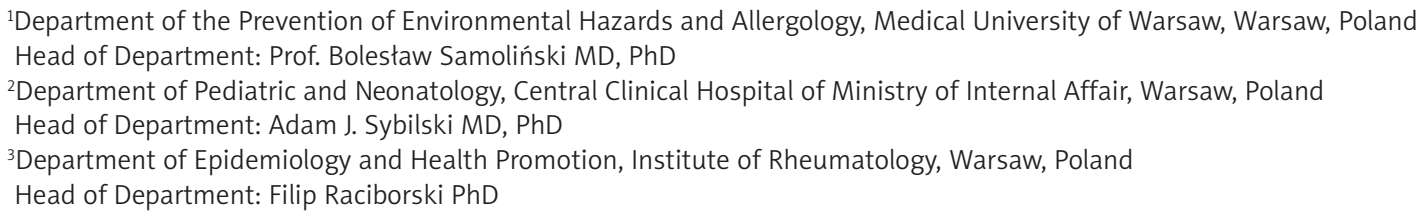

Postep Derm Alergol 2015; XXXII, 1: 1-10 DOI: 10.5114/pdia.2014.40935

\begin{abstract}
Introduction: Global epidemiological studies have revealed considerable geographical differences in prevalence of atopic dermatitis (AD).

Aim: To present the epidemiology of AD, risk factors and co-occurrence of allergic diseases in the Polish population. Material and methods: The present paper is a part of the Epidemiology of Allergic Disorders in Poland study. We studied 22703 participants by ECRHS/ISAAC questionnaire; 18617 (53.8\% female, 24.2\% 6-7 y.o., 25.4\% 13-14 y.o., $50.4 \%$ 20-44 y.o.) completed questionnaires were accepted. Four thousand seven hundred and eighty-three participants (25.7\%) have undergone a medical examination.

Results: Atopic dermatitis was diagnosed in 3.91\% (6-7 y.o. 5.34\%, 13-14 y.0. 4.3\%, adults 3.02\%), more often in females $(\mathrm{OR}=1.52 ; 95 \% \mathrm{Cl}: 0.56-0.77)$, in the cities $(\mathrm{OR}=2.23 ; 95 \% \mathrm{Cl}: 1.61-3.09)$, in mothers $(\mathrm{OR}=2.07 ; 95 \% \mathrm{Cl}$ : $1.72-2.48)$ and fathers $(\mathrm{OR}=2.00 ; 95 \% \mathrm{Cl}: 1.61-2.49)$ with atopy, higher education $(\mathrm{OR}=1.61 ; 95 \% \mathrm{Cl}: 1.11-2.32)$ and economic status $(\mathrm{OR}=1.35 ; 95 \% \mathrm{Cl}: 1.04-1.74)$. The highest prevalence was found in Katowice (4.89\%) and lowest in rural areas (1.9\%). Coexisting AD and allergic rhinitis (AR) was found in $26.17 \%$, AR and asthma in $9.09 \%$ and $A D$, AR and asthma in 14.6\%. Atopic dermatitis was diagnosed by allergologists in 6.5\% (6-7 y.o. 8.7\%, 13-14 y.0. 9.0\%, adults $3.6 \%$ ). Most diagnoses were made in Poznan (16.76\%) and smallest in rural area (3.67\%). $78.8 \%$ of subjects were diagnosed with $A D$ for the first time although they had earlier experienced its symptoms.

Conclusions: Atopic dermatitis prevalence in Poland is below the mean rate for Europe, but the risk factor profile is similar to other countries. Atopic dermatitis is more frequent in well-educated females with atopic parents and high socioeconomic status and who live in a city.
\end{abstract}

Key words: atopic dermatitis, epidemiology, risk factors.

\section{Introduction}

Epidemiological data are a prerequisite for obtaining a fuller picture and better understanding of allergic disorders, including atopic dermatitis (AD), as an important medical and socioeconomic problem [1]. The incidence of allergic disorders has increased in recent years as confirmed by global epidemiological studies (The International Study of Asthma and Allergies in Childhood (ISAAC), The European Community Respiratory Health Survey (ECRHS)), which also revealed considerable geo- graphical differences in prevalence. The ISAAC Phase One found that the prevalence of $A D$ in children and adolescents varied from less than $2 \%$ in China to approximately 20\% in Australia, the United Kingdom and Scandinavia [2, 3]. Harrop et al. [4] conducted an epidemiological study according to ECRHS II protocol in 12 European countries which showed a very considerable variability in the prevalence of eczema in adults aged 20-44 years, the mean prevalence rate being $7.1 \%$ with the lowest rate of $2.2 \%$ reported in Switzerland and the highest

Address for correspondence: Adam J. Sybilski MD, PhD, Department of Pediatric and Neonatology, Central Clinical Hospital of the Ministry of Internal Affairs, 137 Wołoska St, 02-507 Warsaw, Poland, phone: +48 602110653 , fax: +48 22 508 12 22, e-mail: adam.sybilski@cskmswia.pl Received: 18.09.2013, accepted: 28.09.2013. 
rate of $17.6 \%$ reported in Estonia. Although increases in incidences are observed everywhere, rapidly developing countries and the regions with previously relatively low morbidity rates are the most affected.

In the last 30 years, Poland, and Central and East Europe in general have undergone a very deep transformation of the political and economic system with the adoption of Western lifestyle, improved hygiene level, and rapid industrial and economic development. As a result, the number of new cases of allergy-related disorders has increased and now the relevant epidemiological data are similar to those reported in the Western Europe [5]. As early as 2003, this was confirmed by Lis et al. in a study using the ISAAC methodology [6]. In Poland, the first questionnaire-based surveys to estimate the prevalence of allergic disorders were carried out in the 1990s and they confirmed that allergy was a serious epidemiological problem. However, most of the Polish data are derived from small-scale studies conducted in selected cities. In children, depending on the region and diagnostic criteria, the estimated prevalence of $A D$ ranged from $1.6 \%$ [7] to $4.7 \%$ [8] to $5.8 \%$ [9] to $12.9 \%$ [10] to $26.6 \%$ [6] In adults, the prevalence rate ranged from $0.4 \%$ to $1.5 \%$ $[7,8]$. However, the studies assessing the epidemiology of AD did not include rural areas or all regions of Poland, employed different methodology and were based on different material [6, 9-12]. Many authors emphasize that numerous environmental and genetic factors play a role in the development of $A D$ and their contribution depends on the region, intensity and interaction [5]. So far, there have been no comprehensive studies to assess the significance of various risk factors for the development of AD symptoms in the Polish population.

\section{Aim}

The aim of the present study was to evaluate the prevalence of $A D$ in the population of Polish children, adolescents and young adults. In addition, we analyze the role of risk factors and co-morbidity of allergic diseases. The presented work is part of the Epidemiology of Allergic Disorders in Poland (ECAP study).

\section{Material and methods \\ Study group}

A questionnaire survey was carried out on a group of 22703 subjects with the response rate of $64.4 \%$ and eventually 18617 completed questionnaires were accepted. The study involved two age groups of children, 6-7 year olds and 13-14 year olds, and adults aged 20-44. There were 4510 (24.2\%) 6-7 year olds, 4721 (25.4\%) 13-14 year olds and 9386 (50.4\%) adults. Of the respondents 10011 (53.8\%) were females and 8606 (46.2\%) were males. In the medical evaluation part of the study 4783 patients (25.7\% of the respondents) were assessed on an outpatient basis, including 1329 6-7 year olds, 1321 13-14 year olds and 2133 adults.

\section{Methodology}

The ECAP used the methodology of ISAAC and ECRHS II $[2,3,13,14]$ and the study areas were selected according to the ECRHS guidelines. The ECAP involved the populations of eight largest urban agglomerations in Poland (each with over 150000 inhabitants) and additionally one rural region, also with a population of over 150000 since the rural population accounts for $39 \%$ of the entire Polish population. The study areas were specifically chosen but the study subjects were selected by stratified random sampling based on the national identification number PESEL. The Computer Assisted Personal Interviewing (CAPI) technique was used in the survey. The data were transmitted by General Packet Radio Service (GPRS) and recorded online on the server of the Medical University of Warsaw. The system allowed a three-stage quality control.

\section{Questionnaire-based survey}

The questionnaire was based on the translated and validated ECRHS and ISAAC questionnaires. The following diagnostic criteria were accepted.

The diagnosis of AD was made in three stages. When the answer to the question "Have you ever had an itchy rash that was coming and going for at least 6 months?" was "Yes", the subject was directed to the next question "Have you had this itchy rash in the last 12 months?". When the answer again was "Yes", the next question asked was "Has this itchy rash at any time affected any of the following places: the folds of the elbows, behind the knees, in front of the ankles, under the buttocks or around the neck, ears or eyes?". The answer "Yes" meant the diagnosis of atopic dermatitis (Figure 1).

Self-reported AD (s-rAD) was recorded based on the answer to the question "Have you ever had eczema or any kind of skin allergy?" [4, 5, 14].

Allergic rhinitis (AR) was diagnosed when the answer to the question "Do you have any nasal allergies, including hay fever?" was "Yes".

Self-reported asthma (DA) was recorded with the question "Have you ever had asthma?" answered in the affirmative, and symptomatic asthma (SA) when the respondents answered "Yes" when asked "Have you had wheezing or whistling in your chest at any time in the last months?" [2, 13].

The family's economic status was assessed as the joint monthly income from all sources for all members of the household in PLN [converted to $€$ in this paper]. The respondents were classified into three groups by income: < PLN 1500, € 1500-3500 (below the average monthly income for Poland) and > $€ 3500$ (above the average monthly income for Poland). The respondents' education (or the mother's education) was recorded as: primary education (no school education, primary not complet- 




Figure 1. Diagnosis of current reported atopic dermatitis in the questionnaire-based survey

ed, primary plus basic vocational), secondary education (secondary not completed, secondary comprehensive, secondary vocational, post-secondary vocational), higher education (higher not completed, bachelor's degree, master's degree).

\section{Medical evaluation}

Allergologists diagnosed AD (clinically diagnosed atopic dermatitis - CAD) using the Hanifin and Rajka criteria [15], asthma according to the GINA criteria [16] and allergic rhinitis (clinically diagnosed allergic rhinitis - CAR) using the ARIA criteria [17].

\section{Statistical analysis}

A $\chi^{2}$ test or Fisher's exact test (for small sample sizes) were used in the statistical analysis. The $\chi^{2}$ statistics and odds ratio (OR) were calculated to determine the strength of association and dependence between variables. Results were considered to be statistically significant at $p<0.05$.

The study was approved by the institutional Bioethics Committee. It was carried out as part of the project "Implementation of the system for prevention and early diagnosis of allergic disorders in Poland" (No. 6 P05 2005 C/06572) funded by the Minister for Health and the Minister for Science.

\section{Results}

\section{Questionnaire-based survey}

Atopic dermatitis was diagnosed in 3.91\% $(n=727)$ of the subjects, self-reported asthma was found in 4.62\% $(n=857)$, symptomatic asthma in $15.7 \%(n=2914)$, allergic rhinitis in $21.11 \%(n=3913)$ (Table 1$)$. Atopic dermatitis was significantly more frequent in children $(5.34 \%$ 
A.J. Sybilski, F. Raciborski, A. Lipiec, A. Tomaszewska, A. Lusawa, P. Samel-Kowalik, A. Walkiewicz, E. Krzych, J. Komorowski, B. Samoliński

Table 1. Allergic disorders diagnosed based on a questionnaire and physical examination

\begin{tabular}{|c|c|c|c|c|}
\hline Diagnosis & $\begin{array}{c}\text { Total } \\
(n=18617)\end{array}$ & $\begin{array}{l}6-7 \text { year olds } \\
(n=4510)\end{array}$ & $\begin{array}{l}13-14 \text { year olds } \\
(n=4721)\end{array}$ & $\begin{array}{c}\text { Adults } \\
(n=9386)\end{array}$ \\
\hline Atopic dermatitis (AD) & 3.9 & 5.3 & 4.3 & 3.0 \\
\hline Self-reported eczema (s-rAD) & 38.0 & 45.9 & 39.1 & 33.7 \\
\hline Clinically diagnosed atopic dermatitis (CAD) $(n=4783)$ & 6.5 & 8.7 & 9.0 & 3.6 \\
\hline Declared asthma (DA) & 4.6 & 4.4 & 6.2 & 4.0 \\
\hline Symptomatic asthma (AS) & 15.7 & 19.2 & 15.9 & 13.8 \\
\hline Allergic rhinitis (AR) & 22.6 & 23.7 & 24.6 & 21.0 \\
\hline
\end{tabular}

Values in percent.

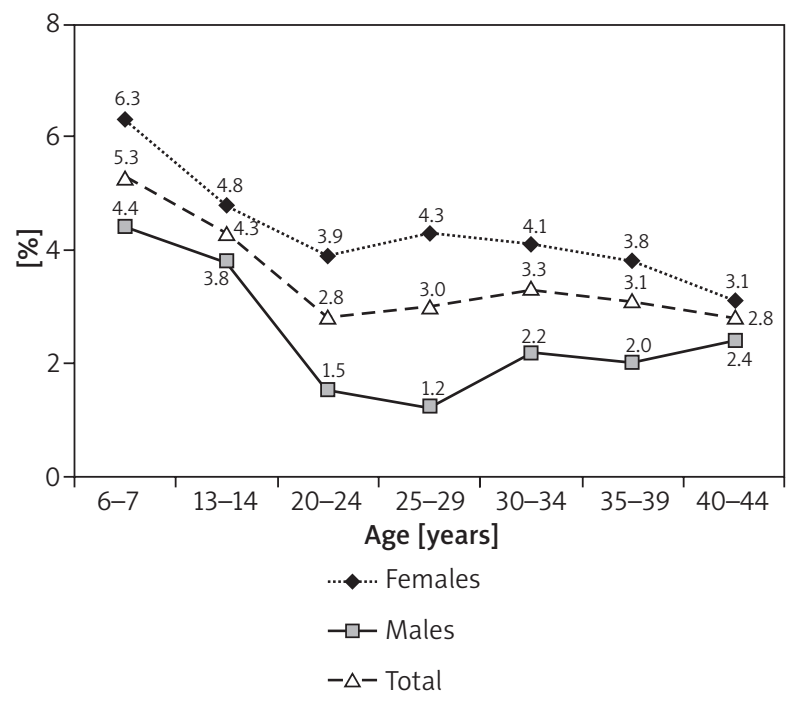

Figure 2. Rates of atopic dermatitis diagnosed in the questionnaire-based survey $(n=18617)$

of 6-7 year olds and $4.30 \%$ of $13-14$ year olds vs. 3.2\% of adults; $p<0.001$ ) (Figure 2). The prevalence of AD was varied depending on the region of Poland (Table 2). The lowest percentage was found in rural areas (Zamosc area) $1.9 \%(n=39)$. Comparing the incidence of $A D$ in urban and rural areas, we noticed more than twice as frequent manifestation of the disease in urban areas (4.1\% vs. $1.9 \%, \mathrm{OR}=2.23,95 \% \mathrm{Cl}: 1.61-3.09, p<0.001)$. Atopic dermatitis was significantly more frequent in females of all age groups (mean prevalence $4.61 \%$ vs. 3.08\%, $\mathrm{OR}=1.52$, 95\% Cl: 1.30-1.77, $p<0.0005$ ) (Figure 2). In the entire population, the self-reported AD was in $37.98 \%$ $(n=7071)$ and depended on the place of residence (Table 2 ) and age (45.8\%, $n=2066$ 6-7 year olds; $39.0 \%$, $n=184213-14$ year olds and 33.7\%, $n=3163$ adults).

Atopic dermatitis was more frequently reported in adults or children of mothers having higher education and in subjects with a higher economic status. A statistically significant association was also established between the diagnosis of AD and atopy in parents and siblings. Atopic dermatitis was more frequently reported in subjects with dampness inside the home (Table 3). However, no correlation was established between AD and other environmental factors (having a twin sibling, $p=0.70$; mother's age, $p=0.93$; body mass index (BMI), $p=0.09$; smoking, $p=0.17$ and exposure to tobacco smoke, $p=0.33$; a cat, $p=0.31$, dog, $p=0.14$ or birds, $p=0.07$ kept inside the house; surface area of the flat (house), $p=0.24$, type of heating, $p=0.32$; how old the building was, $p=0.19$ ).

The concomitant occurrence of AD, declared asthma, asymptomatic asthma and AR in the entire study population are presented in Figure 3. In subjects with diagnosed AD, AD alone was reported in $49.72 \%(n=361)$, coexisting AD and AR in 26.17\% ( $n=190)$, AR and AS in 9.09\% $(n=66)$, and coexisting AD, AR and AS in $14.60 \%(n=106)$.

\section{Medical evaluation}

Four thousand seven hundred eighty-three participants (1329 children aged 6-7 years, 1321 13-14 year olds and 2133 adults) were included in the medical evaluation. Atopic dermatitis was diagnosed in 311 (6.5\%) study subjects (Table 1$)$, including $6.75 \%(n=176)$ of females and $6.21 \%(n=135)$ of males (OR $=1.09,95 \%$ $\mathrm{Cl}: 0.88-1.38, p<0.485)$. Most diagnoses of AD were made in Poznan (16.76\%), Katowice (7.18\%), Lublin (6.98\%), and the smallest in the rural area (3.67\%) (Figure 4). Table 2 shows the prevalence of AD depending on the place of residence. No association was established between either the economic status ( $p=0.199)$ or education ( $p=0.836)$ and the diagnosis of AD established by an allergologist (Table 3).

Table 4 shows the occurrence of atopic dermatitis based on the questionnaires vs. clinically diagnosed atopic dermatitis. The consistency of the questionnaire-based diagnoses and those made by allergologists was estimated at $91.05 \%$. A questionnaire-based diagnosis of $A D$ was confirmed by a physician's evaluation (CAD) in 66 subjects $(1.38 \%)$ while in 4288 subjects $(89.67 \%)$ it was not found by both questionnaire and physician's evaluation. Of the respondents without AD reported from 
Table 2. Atopic dermatitis diagnosed based on a questionnaire and physical examination depending on the place of residence

\begin{tabular}{|c|c|c|c|c|c|c|c|c|c|}
\hline Parameter & Katowice & Warszawa & Wroclaw & Gdansk & Bialystok & Krakow & Lublin & Poznan & Zamosc \\
\hline \multicolumn{10}{|c|}{ Atopic dermatitis based on questionnaire } \\
\hline Total & 4.89 & 4.68 & 4.48 & 4.25 & 4.08 & 3.84 & 3.39 & 3.37 & 1.90 \\
\hline 6-7 year olds & 6.86 & 5.90 & 7.33 & 4.61 & 5.80 & 4.22 & 4.31 & 6.09 & 3.25 \\
\hline $13-14$ year olds & 4.55 & 4.51 & 4.08 & 5.96 & 4.68 & 5.92 & 3.51 & 2.71 & 2.21 \\
\hline Adults & 4.36 & 4.17 & 3.05 & 2.89 & 2.74 & 2.47 & 3.04 & 2.27 & 1.14 \\
\hline \multicolumn{10}{|c|}{ Self-reported eczema } \\
\hline Total & 34.40 & 46.63 & 45.25 & 48.94 & 41.48 & 33.68 & 33.99 & 29.64 & 25.41 \\
\hline $6-7$ year olds & 40.54 & 57.46 & 50.42 & 52.27 & 50.55 & 40.26 & 43.93 & 39.79 & 29.04 \\
\hline 13-14 year olds & 33.32 & 46.13 & 44.61 & 50.84 & 44.26 & 35.13 & 35.94 & 27.45 & 25.08 \\
\hline Adults & 32.71 & 41.67 & 42.40 & 45.63 & 34.77 & 29.12 & 30.01 & 25.43 & 24.03 \\
\hline \multicolumn{10}{|c|}{ Atopic dermatitis based on doctor diagnosis } \\
\hline Total & 7.18 & 6.31 & 6.38 & 5.95 & 4.42 & 2.02 & 6.98 & 16.76 & 3.67 \\
\hline 6-7 year olds & 11.11 & 9.22 & 7.58 & 5.65 & 9.00 & 4.11 & 9.94 & 21.70 & 2.56 \\
\hline $13-14$ year olds & 7.08 & 10.50 & 9.09 & 9.22 & 5.43 & 2.04 & 9.47 & 22.61 & 4.65 \\
\hline Adults & 5.08 & 2.15 & 3.14 & 3.66 & 0.95 & 0.00 & 4.77 & 8.72 & 3.69 \\
\hline
\end{tabular}

Values in percent.

the questionnaire-based survey, a physician diagnosed $A D$ in 245 subjects (5.1\% of the entire study population; 95\% Cl: 4.5-5.7\%) (Table 4). Of the respondents with AD reported from the questionnaire survey $(n=250)$, AD was confirmed by a study allergologist in $26.4 \%$ of the cases. Of the subjects with the clinically diagnosed $\operatorname{AD}(n=311)$, the condition was self-reported in the questionnaires by $21.1 \%$ of the subjects. This finding shows that as many as $78.8 \%(n=245)$ of the subjects undergoing evaluation by an allergologist within ECAP were then first diagnosed with $A D$ although they had earlier experienced its symptoms.

\section{Discussion}

Epidemiological data are a prerequisite for obtaining a fuller picture and better understanding of allergic disorders, including atopic dermatitis, as an important medical and socioeconomic problem. They are also needed to assess the efficacy of prophylactic and therapeutic measures undertaken. It also allows the assessment of the significance of the disease in different age groups and regions, dependent variables of race, gender, living conditions [1]. These objectives guided the conception of aims and methodological principles of the ECAP project. This study is the largest epidemiological study of allergic diseases in Poland and in this part of Europe. Additionally, very important and greatly enhancing the value of this study is the ECAP conducted employing the same methodology as major global epidemiological studies (ISAAC and ECRHS). The sensitivity of those studies, using the same questions and diagnostic criteria, was estimated at $73.1 \%$ and the specificity was $87.3 \%$ in subjects with other skin disorders and $97.1 \%$ in subjects without skin disorders [18].

According the ISAAC Phase Three findings published in 2006, eczema in children was the most prevalent in Scandinavia and the United Kingdom and the least prevalent in Lithuania and Albania (Figure 5) [2]. The prevalence of AD in Poland as estimated by ECAP was in all age groups lower than the European average. ISAAC estimated the prevalence of $A D$ in Polish children at $11.5 \%$ in $6-7$ year olds and $8.5 \%$ in 13-14 year olds, which differs from the present results of our study. The difference might be due to a larger number of children in 8 largest cities as well as in rural areas included in our study. Our findings seem to offer a fuller and more precise picture of the AD epidemiology in Poland. In ECRHS, the mean prevalence of $A D$ in adults was estimated at 7.1\% [4]. Similarly to younger age groups, also in adults the highest prevalence of AD was found in Scandinavia and the United Kingdom. In our findings, the prevalence of AD in adults in Poland is below the mean rate for Europe and similar to the prevalence rates in Spain and Switzerland (Figure 5). The comparison of data from European countries suggests a geographical location is not the main factor affecting the occurrence of AD. The questionnaire-based part of our study showed a statistically significant correlation between the AD symptoms and higher than average income and lower than minimum income. This might explain the position of Poland, a country in an early stage of dynamic development among European 
A.J. Sybilski, F. Raciborski, A. Lipiec, A. Tomaszewska, A. Lusawa, P. Samel-Kowalik, A. Walkiewicz, E. Krzych, J. Komorowski, B. Samoliński

Table 3. Association between environmental factors and diagnosis of AD. Significant values at the $5 \%$ level are in bold

\begin{tabular}{|c|c|c|c|c|c|c|}
\hline \multirow[t]{2}{*}{ Parameter } & \multicolumn{3}{|c|}{ AD based on questionnaire } & \multicolumn{3}{|c|}{$A D$ by doctor diagnosis } \\
\hline & OR & $95 \% \mathrm{Cl}$ & Value of $p$ & OR & $95 \% \mathrm{Cl}$ & Value of $p$ \\
\hline \multicolumn{7}{|l|}{ Gender: } \\
\hline Female $(n=10011)$ & 1.00 & & & & & \\
\hline Male $(n=8606)$ & 0.66 & $0.56-0.77$ & $<0.001$ & 0.91 & $0.73-1.15$ & 0.48 \\
\hline \multicolumn{7}{|l|}{ Monthly salary (PLN): } \\
\hline$<1500(n=2883)$ & 1.00 & & & & & \\
\hline $1500-3500(n=5965)$ & 1.12 & $0.88-1.42$ & 0.08 & 1.24 & $0.84-1.82$ & 0.15 \\
\hline$>3500(n=3177)$ & 1.35 & $1.04-1.74$ & 0.05 & 1.45 & $0.96-2.19$ & 0.19 \\
\hline \multicolumn{7}{|l|}{ Education adults: } \\
\hline Primary $(n=1892)$ & 1.00 & & & & & \\
\hline Secondary $(n=4096)$ & 1.51 & $1.05-2.17$ & 0.03 & 0.87 & $0.43-1.76$ & 0.69 \\
\hline Higher $(n=3330)$ & 1.61 & $1.11-2.32$ & 0.03 & 1.01 & $0.50-2.03$ & 0.83 \\
\hline \multicolumn{7}{|l|}{ Education of the mother: } \\
\hline \multicolumn{7}{|l|}{ 6-7 year olds: } \\
\hline Primary $(n=1098)$ & 1.00 & & & & & \\
\hline Secondary $(n=1874)$ & 1.25 & $0.87-1.80$ & 0.81 & 1.49 & $0.80-2.76$ & 0.78 \\
\hline Higher $(n=1511)$ & 1.62 & $1.13-2.33$ & 0.03 & 2.88 & $1.60-5.17$ & $<0.001$ \\
\hline \multicolumn{7}{|l|}{ 13-14 year olds: } \\
\hline Primary $(n=1330)$ & 1.00 & & & & & \\
\hline Secondary $(n=2141)$ & 0.99 & $0.69-1.42$ & 0.09 & 2.44 & $1.37-4.35$ & $<0.001$ \\
\hline Higher $(n=1182)$ & 1.58 & $1.09-2.30$ & 0.03 & 2.46 & $1.32-4.58$ & $<0.001$ \\
\hline \multicolumn{7}{|l|}{ Familial allergy: } \\
\hline Mother allergy & 2.07 & $1.72-2.48$ & $<0.001$ & 2.19 & $1.68-2.87$ & $<0.001$ \\
\hline Father allergy & 2.00 & $1.61-2.49$ & $<0.001$ & 2.36 & $1.74-3.19$ & $<0.001$ \\
\hline Siblings & 1.84 & $1.55-2.18$ & $<0.001$ & 1.39 & $1.05-1.84$ & 0.01 \\
\hline Moisture in the house & 1.39 & $1.17-1.65$ & $<0.001$ & 1.21 & $1.09-1.54$ & 0.02 \\
\hline
\end{tabular}

countries with lower prevalence rates of AD. The changing economic status of Polish families has a direct impact on their lifestyle and as a result may lead to an increase in the prevalence of $A D$, similar to that observed in more affluent European countries. Simultaneously, the level of education in Poland increases systematically and rapidly, which may also account for the increasing prevalence of $A D$ observed in our study. A higher level of education has been claimed to be of significance for the increased incidence of AD [19-22], although some authors do not agree with the hypothesis [23].

Our findings confirm earlier reports [21, 22], of a significantly more frequent occurrence of $A D$ in children compared to adults. We did not find any significant differences when the adult population was stratified by age (Figure 2). Thus, a decrease in AD prevalence with age is seen in children and adolescents only, while in adults it remains at a similar level irrespective of age.
The prevalence of AD by gender is another important question. In adolescents, Italian [24], Spanish [25], and German [19] studies or the PARSIFAL study [23] showed a more frequent occurrence of AD in girls. We found a similar predominance of females, especially in younger children. However, the opposite tendency or no correlation with gender was seen in several studies carried out outside Europe [21, 26-28]. Only one European study reported a higher prevalence in boys, but the difference was not statistically significant [29]. A higher prevalence of AD may be due to a westernized lifestyle among girls, quality of water or housing conditions in Europe. Similarly, in adults our findings confirmed earlier reports of significantly higher proportions of women with AD compared to men [4, 30]. As suggested by some authors [31], this might reflect very frequent allergic skin disorders of the hands in women, possibly due to more extensive exposure to water and detergents associated with washing, cleaning and cook- 

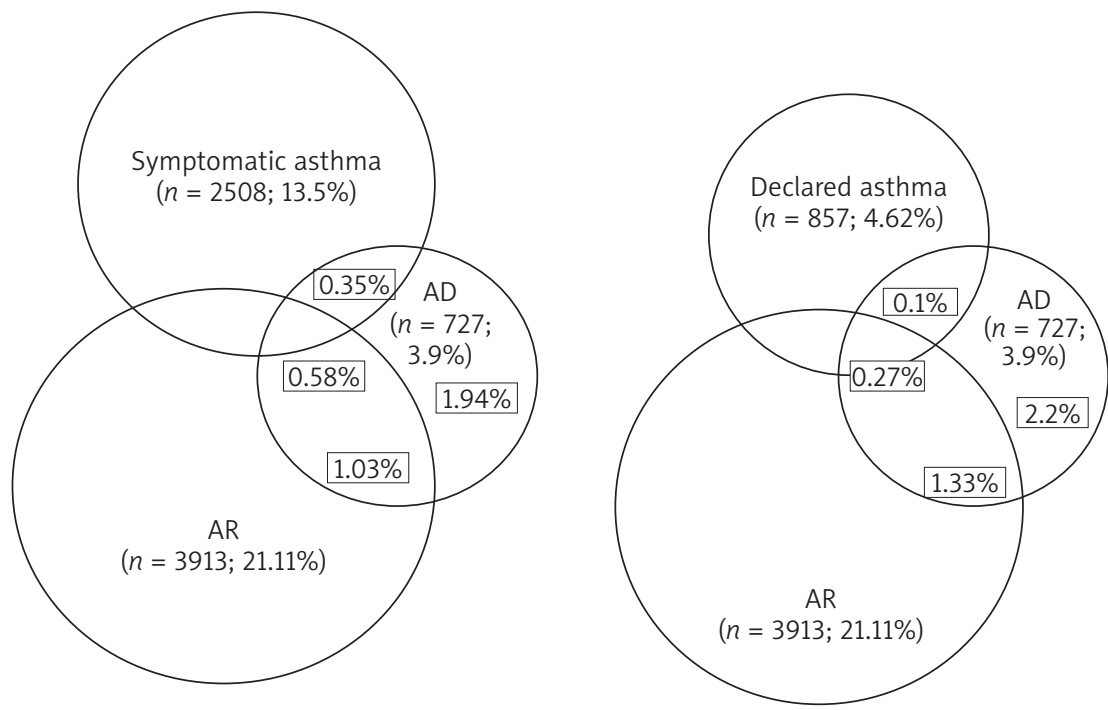

Figure 3. Concomitant occurrence of atopic dermatitis (AD), allergic rhinitis (AR), symptomatic asthma and declared asthma in the entire study population as identified by the questionnaire-based survey $(n=18617)$

ing, although different morphological and physiological features of female skin have also been implicated [22].

Our data indicate a lower prevalence of AD in rural areas compared to cities. A similar tendency was observed in a number of earlier studies from other countries [21, 32-34] and Poland [11] demonstrating the adverse impact of living in big cities on health. The environmental factors may offer the explanation. One factor is less environmental pollution in rural areas [2]. Another, presented by von Hertzen and Haahtela, is the hygiene hypothesis of allergy development whereby increased exposure to microorganisms and plants has a protective function [35]. Additionally, higher hygiene levels (frequent washing and drying of the hands or bath-taking, using large amounts of soap and shower gels) in city dwellers may damage or destroy the natural barrier function of the skin with the resulting development of skin disorders, including $\operatorname{AD}[5,36]$. At the same time, the structure of families living in rural areas (a larger number of children, housing conditions) seems to have a role in the prevention of allergic diseases.

It must be borne in mind that the development or progress of $A D$ is not determined by a single environmental or genetic factor, but by their combinations [5]. Despite numerous studies, we still do not know which of the environmental and genetic factors play a major role. Apart from those discussed earlier, the list of risk factors for $A D$ also includes a family history of atopy, housing conditions and environment or smoking. A positive family history of allergy seems to be the most significant risk factor for AD development $[19,28]$. Our results fully support this hypothesis and are similar to the data reported by other authors $[22,23,37]$. Especially atopy
Table 4. Diagnosis of atopic dermatitis based on the questionnaires vs. clinically diagnosed atopic dermatitis

\begin{tabular}{lccc}
\hline & & \multicolumn{2}{c}{$\begin{array}{c}\text { Atopic dermatitis based on } \\
\text { questionnaire (AD) }\end{array}$} \\
\cline { 2 - 4 } & & Yes & No \\
\hline $\begin{array}{l}\text { Clinically } \\
\text { diagnosed }\end{array}$ & Yes & $66(1.38 \%)$ & $245(5.10 \%)$ \\
\cline { 2 - 4 } $\begin{array}{l}\text { atopic dermatitis } \\
\text { (CAD) }\end{array}$ & No & $184(3.85 \%)$ & $4288(89.67 \%)$ \\
\hline
\end{tabular}

found in one or both parents is a strong risk factor. Thus, a genetic predisposition to atopic disorders seems to be an unquestionable and most important factor in the development of $A D$ and other allergic disorders. There is also a general agreement on the adverse effect of wet or damp spots on surfaces inside the home [19, 22, 38]. Our findings confirm this correlation, but it is of a lesser importance than atopy in family members.

Several studies published in recent years suggest a beneficial effect of close contact with furry pets. In 2007, based on a systematic review Langan suggested that a dog and cat ownership may protect against $\mathrm{AD}$, OR of 0.79 (95\% Cl: 0.62-0.92) and of $0.68(95 \% \mathrm{Cl}$ : 0.53-0.87), respectively [39]. Newer studies do not report this significant effect of close contact with the cat and dog $[19,23,24,28]$. In the present study, no correlation between allergy and a cat or a dog in the home was established [40]. This discrepancy points to the need for further studies to confirm or refute the earlier hypothesis of a beneficial effect of furry pets. 


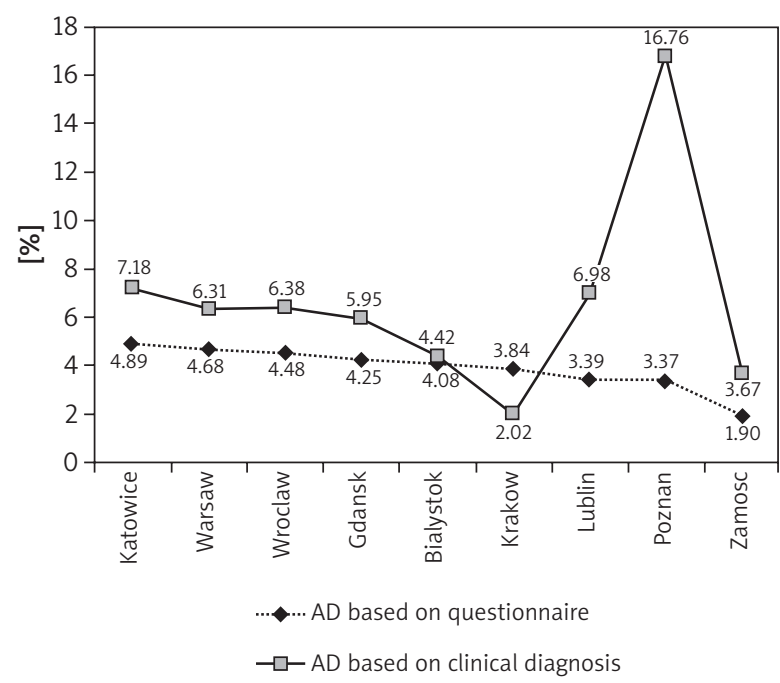

Figure 4. Diagnosis of atopic dermatitis based on the questionnaires $(n=18617)$ vs. clinically diagnosed atopic dermatitis $(n=4783)$ depending on place of residence

Our study did not confirm either the significance of such factors as smoking cigarettes, exposure to tobacco smoke, flat (house) size, maternal age, BMI or mode of delivery. No correlation between the above factors and AD has been confirmed by other recent studies [21-23].

The results of a questionnaire-based survey should be verified by laboratory investigations and assessment by physicians who make a more precise diagnosis based on physical examination. A study by Flohr et al. showed flexural eczema in 3.9\% of patients examined by a physician vs. 9.4\% identified from questionnaires (ISAAC Phase Two) [41]. It showed that, based on the questionnaire, AD is overdiagnosed. This aspect was pointed out by a group of Polish investigators [42, 43]. In our study, on the other hand, significantly more cases of AD were identified by physicians (6.5\%) than were self-reported in the questionnaires (3.9\%). This proves that a properly conducted survey on adequately prepared questionnaires is methodologically a reliable source of information on the epidemiology of AD. Proper translation and validation of the original questionnaire is the most crucial, which is particularly emphasized by the authors of the original English-speaking questions [44]. A larger number of diagnoses based on doctor examination may indicate that medical examination is likely to be preferred and come more frequently for people with health problems than healthy ones, which can in some way falsify the results. Perhaps this situation occurred in our study in the Poznan center (diagnoses based on medical examination are almost five times higher than diagnoses based on the questionnaire) and Lublin. This could have an impact on the overall frequent detection of $A D$ in clinical examination.

When the agreement of the two kinds of diagnosis, i.e. made by a study physician and self-reported was analyzed, AD was found to be seriously underdiagnosed in Poland. Out of the study subjects undergoing evaluation by an allergologist as many as 78.8\% were first diagnosed with $A D$ although they had developed the symp-
Children aged 6-7 years

\begin{tabular}{|c|c|}
\hline Lithuania & $\bullet 3.0 \%$ \\
\hline Albania & $\bullet 3.7 \%$ \\
\hline Ukraine & . $5.3 \%$ \\
\hline $\begin{array}{c}\text { Poland } \\
\text { (ECAP) }\end{array}$ & $\bullet$ \\
\hline Spain & • $5.9 \%$ \\
\hline Austria & $\bullet 6.1 \%$ \\
\hline Russia & $\bullet 6.6 \%$ \\
\hline Germany & $\bullet 7.9 \%$ \\
\hline Portugal & • $9.7 \%$ \\
\hline Italy & $\bullet 10.1 \%$ \\
\hline Estonia & • $11.5 \%$ \\
\hline Poland & $\bullet 11.5 \%$ \\
\hline Belgium & $\bullet 11.6 \%$ \\
\hline $\begin{array}{r}\text { United } \\
\text { Kingdom }\end{array}$ & • $16.0 \%$ \\
\hline Sweden & $23.3 \%$ \\
\hline
\end{tabular}

Children aged 13-14 years



Adults

\begin{tabular}{|r|c|}
$\begin{array}{r}\text { Switzer- } \\
\text { land }\end{array}$ & $\bullet 2.2 \%$ \\
Poland \\
ECAP) & $\bullet 3.02 \%$ \\
Spain & $\bullet 4.2 \%$ \\
\hline Germany & $\bullet 5.1 \%$ \\
Belgium & $\bullet 5.9 \%$ \\
Italy & $\bullet 6.6 \%$ \\
$\begin{aligned} \text { USA } \\
\text { (Portland) }\end{aligned}$ & $\bullet 7.4 \%$ \\
France & $\bullet 8.0 \%$ \\
$\begin{array}{r}\text { United } \\
\text { Kingdom }\end{array}$ & $\bullet 8.1 \%$ \\
Iceland & $\bullet 8.1 \%$ \\
$\begin{array}{r}\text { Norway } \\
\text { Sweden }\end{array}$ & $\bullet 8.6 \%$ \\
$\begin{array}{r}\text { Estonia } \\
\text { (Tartu) }\end{array}$ & $\bullet 9.0 \%$ \\
\hline
\end{tabular}

Figure 5. Epidemiology of atopic dermatitis according to ISAAC, ECRHS and ECAP studies [2, 4 modified by authors] 
toms earlier. This finding may suggest underdiagnosis of $A D$ in Poland, but on the other hand it may result from the imprecise definition of $A D$ in the questionnaire and the methodology of recognizing AD used in the study. A respondent is required to answer questions about skin changes (an itchy rash) at an unspecified time in the past ("Have you ever had...") and in the last 12 months, which may falsify the data. This pitfall has already been identified by Zutavern et al. [19]. Thus, we cannot ignore the number of "Yes" answers to one question about having ever had skin changes suggestive of allergy. The question is very general and non-specific so the "Yes" answer cannot be treated as the diagnosis of AD. Overall, as many as 38\% of the respondents answered "Yes". The question though non-specific, is characterized by a very high sensitivity and the answer identifies the number of people with any skin problem. When comparing the ECAP findings with the ISAAC data published in 2008, the proportion of "Yes" answers in the Polish pediatric population is similar to the countries with the highest rates (Sweden $38.6 \%$ and the UK $36.1 \%$ ) [5]. In addition, in adults, the percentage of self-declared eczematous changes at any time reported in our study was similar to the ECRHS findings, i.e. $38.4 \%$ on average [4].

Studies in large groups of children and adolescents have demonstrated that AR coexists with AD in 8\% [45] to over $21 \%$ of cases [19]. Asthma accompanies AD in fewer cases, although in some studies concomitant AD and asthma were found in $23.2 \%$ [ 46 ] and $19.6 \%$ of subjects [19]. Our study confirms the tendency of more frequent coexistence of $A R$ and $A D$ than of asthma and $A D$. Over $40 \%$ of AD patients had the coexisting symptoms of $A R$ and in $23.7 \%$ of the subjects skin manifestations were associated with wheezes (AS). This finding shows that allergic disorders affect many organ systems and $A D$ patients should be evaluated for AR and asthma with preventive measures introduced when necessary.

\section{Conclusions}

The findings of the reported study clearly demonstrate that $A D$ is a serious health problem in Poland, although its prevalence is below the mean rate for Europe. Based on our data, we can assume that from $4 \%$ to $6.5 \%$ of the Polish population suffers from AD. It gives approximately 1.5 to 2.5 million people. It should also be noted that due to the methodology of project, we included children aged 6-7 and 13-14 years and 20-44 year-old adults, which is not the age range in which $A D$ is the most common. It gives you assume that younger children have atopic dermatitis is more common, and is therefore a very serious medical and socioeconomic problem. When different risk factors were assessed it was found that AD should be more frequently expected in girls whose parents suffer from atopic disease themselves, are well educated, with a high socioeconomic status, and live in a city.

\section{Acknowledgments}

The study was performed in collaboration with Professor Anna Bodzenta-Łukaszyk (Bialystok), Professor Anna Bręborowicz (Poznan), Professor Andrzej Emeryk (Lublin), Professor Andrzej M. Fal (Wroclaw), Professor Radosław Gawlik (Zabrze), Professor Wiesław Gliński (Warsaw), Teresa Hofman Ph.D. (Poznan), Professor Mirosław Jarosz (Lublin), Professor Ewa Jassem (Gdansk), Professor Piotr Kuna (Lodz), Professor Jerzy Kruszewski (Warsaw), Professor Teresa Kulik (Lublin), Professor Marek Kulus (Warsaw), Professor Grzegorz Lis (Krakow), Professor Sławomir Majewski (Warsaw), Professor Michał Musielak (Poznan), Professor Barbara Rogala (Katowice), Professor Wojciech Silny (Poznan), Professor Andrzej Szpak (Bialystok), and Professor Jan Zejda (Katowice).

\section{Conflict of interest}

The authors declare no conflict of interest.

\section{References}

1. Torres-Borrego J, Molina-Terán AB, Montes-Mendoza C. Prevalence and associated factors of allergic rhinitis and atopic dermatitis in children. Allergol Immunopathol 2008; 36: 90-100.

2. Asher MI, Montefort S, Björkstén B, et al. Worldwide time trends in the prevalence of symptoms of asthma, allergic rhinoconjunctivitis, and eczema in childhood: ISAAC Phases One and Three repeat multicountry cross-sectional surveys. Lancet 2006; 368: 733-43.

3. Odhiambo JA, Williams HC, Clayton TO, et al. Global variations in prevalence of eczema symptoms in children from ISAAC Phase Three. J Allergy Clin Immunol 2009; 124: 1251-8.

4. Harrop J, Chinn S, Verlato G, et al. Eczema, atopy and allergen exposure in adults: a population-based study. Clin Exp Allergy 2007; 37: 526-35.

5. Williams $\mathrm{H}$, Stewart $\mathrm{A}$, von Mutius E, et al. Is eczema really on the increase worldwide? I Allergy Clin Immunol 2008; 121: 947-54.

6. Lis G, Bręborowicz A, Cichocka-Jarosz E, et al. Increasing prevalence of allergic diseases in Poland - results of International Study of Asthma and Allergies in Childhood. Alergia 2003; 3:16-17.

7. Stelmach I, Smejda K, Kaczmarek J, et al. Prevalence of atopy and atopic diseases in children living in an orphanage in Lodz area: pilot study. Pol Merkur Lekarski 2006; 20: 531-4.

8. Małolepszy J, Liebhart J, Wojtyniak B, et al. Prevalence of allergic diseases in Poland. Alergia Astma Immunol 2000; 5 (Suppl. 2): 163-9.

9. Kupryś-Lipińska I, Elgalal A, Kuna P. The epidemiology of atopic dermatitis in the general population of the Łódź province's citizens. Pneumonol Alergol Pol 2009; 77: 145-51.

10. Breborowicz A, Burchardt B, Pieklik H. Asthma, allergic rhinitis and atopic dermatitis in schoolchildren. Pneumonol Alergol Pol 1995; 63: 157-61.

11. Czarnecka-Operacz M, Jenerowicz D, Silny W. Non-allergic type of atopic dermatitis among patients of Allergic Diseases Diagnostic Center, University of Medical Sciences in Poznań. Przegl Lek 2005; 62: 1332-6. 
12. Lis G, Breborowicz A, Swiatły A, et al. Prevalence of allergic diseases in schoolchildren in Krakow and Poznan (based on a standardized ISAAC questionnaire). Pneumonol Alergol Pol 1997; 65: 621-7.

13. European Community Respiratory Health Survey: Variations in the prevalence of respiratory symptoms, self-reported asthma, and use of asthma medication in the European Community Respiratory Health Survey. Eur Respir J 1996; 9: 687-95.

14. ISAAC Steering Committee. International Study of Asthma and Allergies in Childhood Manual. Auckland/Münster; 1993. Available at: http://isaac.auckland.ac.nz/ PhaseOne/ Manual/ManFrame.html. Accessed December 3, 2007.

15. Hanifin JM, Rajka G. Diagnostic features of atopic dermatitis. Acta Dermatol Venerol 1980; 92: 44-7.

16. National Heart LaBI. Global Initiative for Asthma. Global strategy for asthma management and prevention. Bethesda, National Institutes of Health 1995.

17. Bousquet J, Van Cauwenberge P, Khaltaev N; Aria Workshop Group; World Health Organization. Allergic rhinitis and its impact on asthma. J Allergy Clin Immunol 2001; 108 (5 Suppl.): S147-334.

18. Williams HC, Burney PG, Hay RJ, et al. The U.K. Working Party's Diagnostic Criteria for Atopic Dermatitis. I. Derivation of a minimum set of discriminators for atopic dermatitis. $\mathrm{Br}$ J Dermatol 1994; 131: 383-96.

19. Zutavern A, Hirsch T, Leupold W, et al. Atopic dermatitis, extrinsic atopic dermatitis and the hygiene hypothesis: results from a cross-sectional study. Clin Exp Allergy 2005; 35: 1301-8.

20. Harris JM, Cullinan P, Williams HC, et al. Environmental associations with eczema in early life. Br J Dermatol 2001; 144 795-802.

21. Shaw TE, Currie GP, Koudelka CW, et al. Simpson Eczema Prevalence in the United States: Data from the $2003 \mathrm{Na}$ tional Survey of Children's Health. J Invest Dermatol 2011; 131: 67-73.

22. Lee YL, Li CW, Sung FC, et al. Environmental factors, parental atopy and atopic eczema in primary-school children: a cross-sectional study in Taiwan. Br J Dermatol 2007; 157: 1217-24.

23. Karadag B, Ege MJ, Scheynius A, et al. Environmental determinants of atopic eczema phenotypes in relation to asthma and atopic sensitization. Allergy 2007; 62: 1387-93.

24. Brescianini S, Brunetto B, lacovacci $P$, et al. Prevalence of self-perceived allergic diseases and risk factors in Italian adolescents. Pediatr Allergy Immunol 2009; 20: 578-84.

25. Aragones AM, Toledo RF, Calatayud AM, et al. Epidemiolog ic, clinical and socioeconomic factors of atopic dermatitis in Spain: Alergologica-2005. J Investig Allergol Clin Immunol 2009; 19 (Suppl. 2): 27-33.

26. Zar HJ, Ehrlich RI, Workman L, et al. The changing prevalence of asthma, allergic rhinitis and atopic eczema in African adolescents from 1995 to 2002. Pediatr Allergy Immunol 2007; 18: 560-5.

27. Behbehani NA, Abal A, Syabbalo NC, et al. Prevalence of asthma, allergic rhinitis, and eczema in 13- to 14-year-old children in Kuwait: an ISAAC study. International Study of Asthma and Allergies in Childhood. Ann Allergy Asthma Immunol 2000; 85: 58-63.

28. Hon KLE, Leung TF, Lam MC, et al. Which aeroallergens are associated with eczema severity? Clin Exp Dermatol 2007; 32: $401-4$
29. Naldi L, Parazzini F, Galus S. Prevalence of atopic dermatitis in Italian schoolchildren: factors affecting its variation. Acta Derm Venereol 2009; 89: 122-5.

30. Hwang CY, Chen YJ, Lin MW et al. Prevalence of atopic dermatitis, allergic rhinitis and asthma in Taiwan: a national study 2000 to 2007. Acta Derm Venereol 2010; 90: 589-94.

31. Montnemery P, Nihlen U, Goran LC, et al. Prevalence of self-reported eczema in relation to living environment, socio-economic status and respiratory symptoms assessed in a questionnaire study. BMC Dermatol 2003; 3: 4.

32. Mercer MJ, Joubert G, Ehrlich RI, et al. Socioeconomic status and prevalence of allergic rhinitis and atopic eczema symptoms in young adolescents. Pediatr Allergy Immunol 2004; 15: 234-41.

33. Addo Yobo EO, Custovic A, Taggart SC, et al. Exercise induced bronchospasm in Ghana: differences in prevalence between urban and rural schoolchildren. Thorax 1997; 52: 161-5.

34. Yemaneberhan H, Bekele Z, Venn A, et al. Prevalence of wheeze and asthma and relation to atopy in urban and rural Ethiopia. Lancet 1997; 350: 85-90.

35. von Hertzen L, Haahtela T. Disconnection of man and the soil: reason for the asthma and atopy epidemic. J Allergy Clin Immunol 2006; 117: 334-44.

36. Sherriff A, Golding J. Hygiene levels in a contemporary population cohort are associated with wheezing and atopic eczema in preschool infants. Arch Dis Child 2002; 87: 26-9.

37. Peroni DG, Piacentini GL, Bodini $A$, et al. Prevalence and risk factors for atopic dermatitis in preschool children. Br J Dermatol 2008; 158: 539-43.

38. Savilahti R, Uitti J, Roto P, et al. Increased prevalence of atopy among children exposed to mold in a school building. Allergy 2001; 56: 175-9.

39. Langan SM, Flohr C, Williams HC. The role of furry pets in eczema: a systematic review. Arch Dermatol 2007; 143: 1570-7.

40. Epstein TG, Bernstein DI, Levin L, et al. Opposing effects of cat and dog ownership and allergic sensitization on eczema in an atopic birth cohort. J Pediatr 2011; 158: 265-71.

41. Flohr C, Weinmayr G, Weiland SK, et al. How well do questionnaires perform compared with physical examination in detecting flexural eczema? Findings from the International Study of Asthma and Allergies in Childhood (ISAAC) Phase Two. Br J Dermatol 2009; 161: 846-53.

42. Czarnobilska E, Obtulowicz K, Dyga W, et al. A half of schoolchildren with 'ISAAC eczema' are ill with allergic contact dermatitis. J Eur Acad Dermatol Venereol 2011; 25: 1104-7.

43. Spiewak R, Czarnobilska E. Not all that looks like eczema is atopic eczema. J Eur Acad Dermatol Venereol 2011; 25: 992-3.

44. Flohr C, Williams HC. Childhood eczema according to the International Study of Asthma and Allergies in Childhood (ISAAC) questionnaire tool - response to Czarnobilska et al. J Eur Acad Dermatol Venereol 2011; 25: 993-4.

45. Clausen M, Kristjansson S, Haraldsson A, et al. High prevalence of allergic diseases and sensitization in a low allergen country. Acta Paediatr 2008; 97: 1216-20.

46. Ergin S, Ozşahin A, Erdoğan BS, et al. Epidemiology of atopic dermatitis in primary schoolchildren in Turkey. Pediatr Dermatol 2008; 25: 399-401. 